\title{
Pattern Analysis of Driver's “Pressure-State-Response” in Traffic Congestion
}

\author{
Weiwei Qi, ${ }^{1}$ Yulong Pei, ${ }^{2}$ Mo Song, ${ }^{3}$ and Yiming Bie ${ }^{1}$ \\ ${ }^{1}$ School of Transportation Science and Engineering, Harbin Institute of Technology, Harbin 150090, China \\ ${ }^{2}$ College of Traffic, Northeast Forestry University, Harbin 150040, China \\ ${ }^{3}$ Department of Automobile Service Engineering, Zhejiang Traffic Technician College, Jinhua 321000, China
}

Correspondence should be addressed to Weiwei Qi; qwwhit@163.com

Received 25 September 2013; Revised 4 November 2013; Accepted 10 November 2013

Academic Editor: Huimin Niu

Copyright (C) 2013 Weiwei Qi et al. This is an open access article distributed under the Creative Commons Attribution License, which permits unrestricted use, distribution, and reproduction in any medium, provided the original work is properly cited.

\begin{abstract}
Traffic congestion, which has a direct impact on the driver's mood and action, has become a serious problem in rush hours in most cities of China. Currently, the study about driver's mood and action in traffic congestion is scarce, so it is necessary to work on the relationship among driver's mood and action and traffic congestion. And the PSR (pressure-state-response) framework is established to describe that relationship. Here, PSR framework is composed of a three-level logical structure, which is composed of traffic congestion environment, drivers' physiology change, and drivers' behavior change. Based on the PSR framework, various styles of drivers have been chosen to drive on the congested roads, and then traffic stream state, drivers' physiology, and behavior characters have been measured via the appropriative equipment. Further, driver's visual characteristics and lane changing characteristics are analyzed to determine the parameters of PSR framework. According to the PSR framework, the changing law of drivers' characteristics in traffic congestion has been obtained to offer necessary logical space and systematic framework for traffic congestion management.
\end{abstract}

\section{Introduction}

Traffic congestion has become a peculiar phenomenon in rush hour of big city, and the rapid increasing number of automobiles and comparable insufficiency of transportation facilities are the direct reason [1]. So, scholars usually research the causes, formation mechanism, and mitigation strategies of traffic congestion from the perspective of traffic supply and traffic demand. Arnott [2] established a bathtub model of downtown rush-hour traffic congestion to perfect the standard economic models of traffic congestion. Tsekeris and Geroliminis [3] analyzed the relationship between land use and traffic congestion by employing the macroscopic fundamental diagram, which constitutes robust second-best optimal strategies that can further reduce congestion externalities. Traffic congestion prediction plays an important role in route guidance and traffic management [4], and many traffic congestion prediction models have been proposed by scholars, such as the nearest neighbor method [5], the ARIMA (autoregressive integrated moving average) model [6] and the vector ARMA (autoregressive moving average) model [7].

Traffic congestion has brought huge economic losses and adverse impact on the driver's mood [8]. Traffic congestion increases the drivers' physiological pressures and the burdens of visual cognition [9], which leads to risky driving behavior [10]. So, "perception-judgment-decision" process reflects the formation mechanism for the driving behavior in rush hour of urban road.

According to statistical data, $70 \%$ of the driver's perception information is based on visual system, and many studies have recorded and analyzed drivers' eye movements. Lansdown [11] completed a study in which visual allocation and verbal reports were recorded to determine individual differences in drivers conducting in-vehicle tasks. Underwood et al. [12] argued that it was common sense that a driver must look at the appropriate locations in a traffic scene in order to gain information about risks and potential risks in the scene. Benedetto et al. [13] obtained more short blinks that occur 


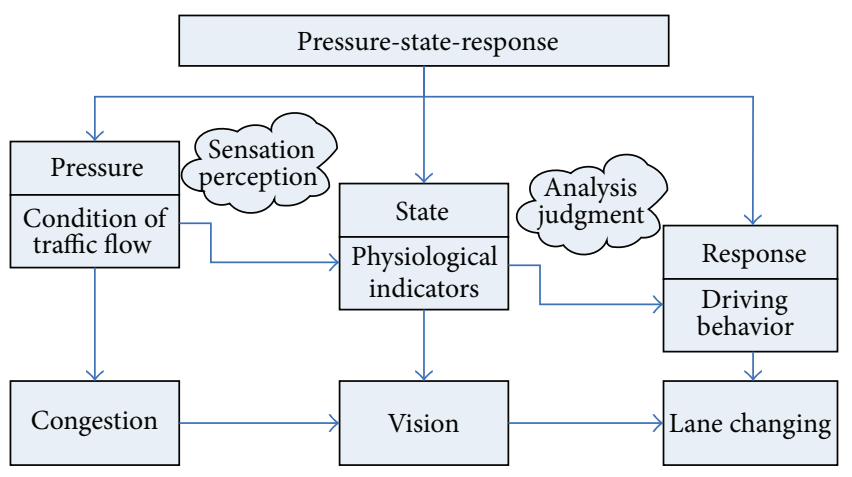

FIGURE 1: Model of driver's “pressure-state-response”.

with an IVIS (in-vehicle information systems) interaction during driving, while more long blinks arise as time spent driving increases.

In various driving situations, drivers with higher trait tendencies are considered more likely to experience frequent and intense emotional states [14]. The influence of driving anger tendencies on the driver's behavior has not been clear. Anger-prone drivers have reported driving at higher speed and with less speed limit compliance as well as more near accidents $[15,16]$, less concentration, and reduced vehicular control while driving $[14,15]$.

So, traffic congestion would have a negative impact on the mood of the drivers on urban road [8], which will be reflected in the eye movements and driving behavior characteristics. This paper attempts to explore the regular pattern for "traffic congestion-eye movement-driving behavior."

\section{2. "Pressure-State-Response" Model of Drivers in Traffic Congestion}

In 1979, Rapport et al. [17, 18] proposed a PSR (pressurestate-response) model and concluded that humans and all other biota coevolve with their environments. Then, the PSR model was widely used in ecological security assessment, land quality assessment, evaluation of sustainable land use, and ecosystem health assessment $[19,20]$. In the state of traffic congestion, the interaction between drivers and traffic environment can be described through an improved PSR model, as shown in Figure 1. So, the definition and structure for the improved PSR model are the research focus of this section. In order to explore the regular pattern for the improved PSR model (pressure-traffic congestion, state-eye movement, and response-lane changing), the frame model in traffic congestion can be regarded as a three-level logical structure, which can be explained as follows.

(1) Pressure-traffic congestion: drivers start a travel with some purposes, and they want to drive under a desired speed, but the traffic congestion will reduce the speed of their vehicles. Daily driving, particularly in congestion condition, can be viewed as a frequent source of stress [21]. Therefore, the pressure can be measured by the degree of traffic congestion.
(2) State-eye movement: it is the change of drivers' physiological indexes under the condition of traffic congestion, which can be measured by driver's visual characteristics, such as fixation points' distribution, fixation duration, average saccade speed, average saccade acceleration, blink duration, and blink rate.

(3) Response-lane changing: drives' stress has been found to subsequently influence mood, thoughts, feelings, and behaviors [22]. The response is the driving action that drivers take under the specific physiological condition due to traffic congestion, and the response can be measured by driver's lane changing characteristics.

\section{Source Pressure for Drivers in Traffic Congestion}

Traffic congestion is the loss of travel time and running speed for divers; thus, pressure coefficient $\chi_{\text {press }}^{t_{0}-t_{n}}$ is defined to express the stress that drivers are subjected to in traffic congestion. Pressure coefficient $\chi_{\text {press }}^{t_{0}-t_{n}}$, which is the product of divers' time and speed, is a cumulative index due to traffic congestion from $t_{0}$ to $t_{n}$ in rush hour. It can be shown as follows:

$$
\chi_{\text {press }}^{t_{0}-t_{n}}=\frac{\left(\int_{t=t_{0}}^{t_{n}} V_{\text {off-peak }}(t) d t-\int_{t=t_{0}}^{t_{n}} V_{\text {rush }}(t) d t\right)}{\int_{t=t_{0}}^{t_{n}} V_{\text {off-peak }}(t) d t},
$$

where $\chi_{\text {press }}^{t_{0}-t_{n}}$ is the pressure coefficient of drivers driving on route $S$ from $t_{0}$ to $t_{n}$ during rush hour, $\mathrm{km} ; V_{\text {rush }}(t)$ is the function of time, representing driving speed on route $S$ during rush hour, $\mathrm{km} / \mathrm{h} ; V_{\text {off-peak }}(t)$ is the function of time, representing driving speed on route $S$ during nonrush hour, $\mathrm{km} / \mathrm{h}$; $t$ is the travel time of drivers, $\mathrm{h} ; t_{0}$ is the departure time of drivers on route $S$ during rush hour, $\mathrm{h} ; t_{n}$ is the arrival time of drivers on route $S$ during rush hour, h.

According to the definition of the pressure coefficient in traffic congestion, it can be simplified as follows:

$$
\begin{gathered}
\chi_{\text {press }}^{t_{0}-t_{n}=} \frac{\left[\bar{V}_{\text {off-peak }} \cdot\left(t_{n}-t_{0}\right)-\bar{V}_{\text {rush }} \cdot\left(t_{n}-t_{0}\right)\right]}{\left[\bar{V}_{\text {off-peak }} \cdot\left(t_{n}-t_{0}\right)\right]}, \\
\chi_{\text {press }}^{t_{0}-t_{n}}=\frac{\left(\bar{V}_{\text {off-peak }}-\bar{V}_{\text {rush }}\right)}{\bar{V}_{\text {off-peak }}},
\end{gathered}
$$

where $\bar{V}_{\text {rush }}$ is the average speed of vehicles on route $S$ during rush hour, $\mathrm{km} / \mathrm{h} ; \bar{V}_{\text {off-peak }}$ is the average speed of vehicles on route $S$ during nonrush hour, $\mathrm{km} / \mathrm{h}$.

Evaluation questionnaire on traffic congestion is a draft based on the definition of the pressure coefficient in traffic congestion, and the analyzing results of 1000 questionnaires are shown in Figure 2. The statistical results of 1000 questionnaires are fitted to normal distribution function $(\mu=0.5087$, $\sigma=0.1361$, and $R^{2}=0.9656$ ); therefore, pressure coefficient for the $85 \%$ cumulative frequency value is 0.65 ; thus $\chi_{\text {press }}^{t_{0}-t_{n}}=$ 0.65 can be treated as the threshold value to classify the road traffic volume state. When $\chi_{\text {press }}^{t_{0}-t_{n}}<0.65$, traffic volume can 


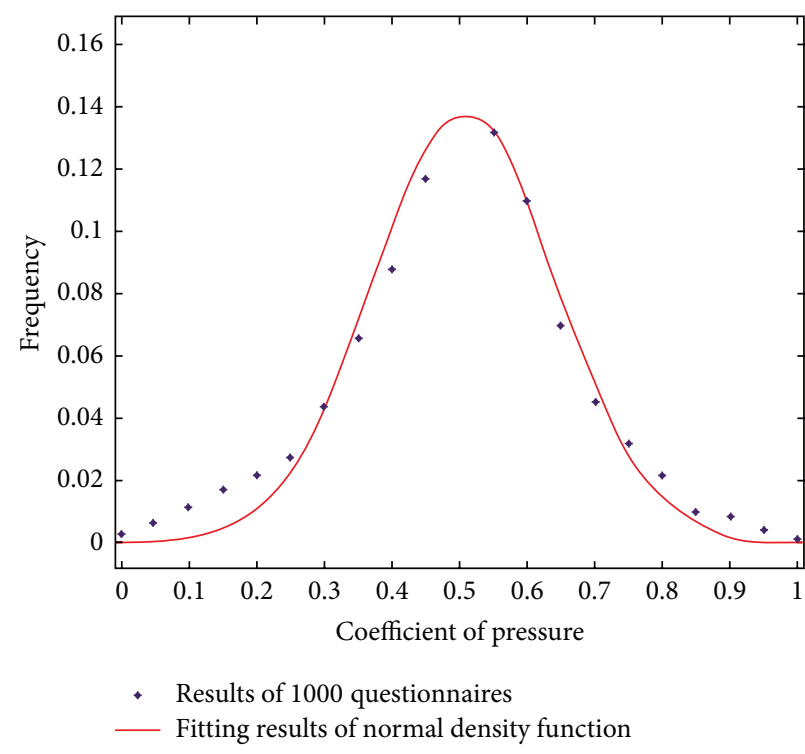

(a)

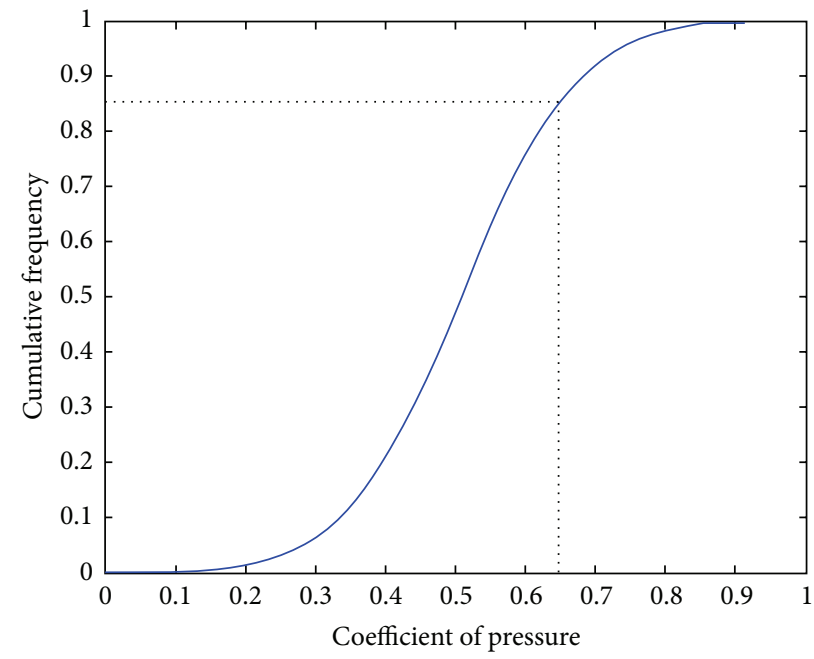

(b)

FIGURE 2: Evaluation results of pressure coefficient in traffic congestion.

be regarded as being in general state; while $\chi_{\text {press }}^{t_{0}-t_{n}}>0.65$, it is in the congested state. Next, the drivers' visual characteristics and lane changing characteristics will be compared separately during the two states.

\section{Driver's Visual Characteristics in Traffic Congestion}

4.1. Experimental Design. Eighty drivers (30 females, mean age $=33, \min =21, \max =50$, and $\mathrm{SD}=8 ; 50$ males, mean age $=36, \min =21, \max =58$, and $\mathrm{SD}=11$ ) were recruited and informed about the experiment's general purposes. All of them declared that they had valid Chinese driving licenses, with a mean of 9 years of driving experience. The dynamic visual characteristics of the drivers are selected as indicators of "state" on the basis for pressure source of traffic congestion, and the test scenarios of drivers' visual characteristics are shown in Figure 3. All participants were informed about the possibility of giving up (without any consequences) at any time if they did not feel comfortable during the experiment. All of them finished the process about data recording of their eye movements and driving performance in the general and congested state (that two states are distinguished via formula (3) and the threshold value of $\chi_{\text {press }}^{t_{0}-t_{n}}$.

Whether the change of drivers' eye movements is obvious and what kind of characteristics drivers' vision may have in traffic congestion are studied based on the test about the eye movement characteristics of 80 drivers in general and congested state via an SMI iView X HED head-mounted monocular eye tracker. The test indicators (dependent variables) of participants' eye movements are shown in Table 1.

\subsection{Eye Fixation}

4.2.1. Fixation Points' Distribution. Similarities and differences of fixation points in general and congested state are represented by the coordinates, and this indicates the spatial
TABLE 1: Indexes of drivers' visual characteristics in general and congested state.

\begin{tabular}{lcl}
\hline No. & Types of eye movements & Indexes of eye movements \\
\hline 1 & Fixation & $\begin{array}{l}\text { Fixation points' distribution } \\
\text { Fixation duration }\end{array}$ \\
\hline 2 & Saccade & $\begin{array}{l}\text { Average saccade speed } \\
\text { Average saccade acceleration }\end{array}$ \\
\hline 3 & Blink & $\begin{array}{l}\text { Blink duration } \\
\text { Blink rate }\end{array}$ \\
\hline
\end{tabular}

distribution of the fixation points. $x$-axis of the horizon plane is divided into 800 units and $y$-axis is divided into 600 units, as shown in Figure 4. According to Figure 4, in general state, fixation points of divers are mainly accumulated in an area where $x$-axis is from 150 to 500 and $y$-axis is from 300 to 550 , while, in congested state, fixation points of divers are mainly accumulated in an area where $x$-axis is from 100 to 600 and $y$ axis is from 200 to 500 . So, the space range of fixation points' distribution in congested state is 1.7 times that of in general state.

4.2.2. Fixation Duration. The fixation duration is an important indicator of the drivers' visual capacity allocation. And the results of statistical analysis are shown in Table 2. The mean value and standard deviation of the fixation duration are different in general and congested state. From Figures 5 and 6 , it can be concluded that the fixation duration in general and congested state generally obeys log-normal distribution other than normal distribution.

\subsection{Eye Saccade}

4.3.1. Average Saccade Speed. The statistical analysis results of drivers' average saccade speed are shown in Table 3 . The mean 


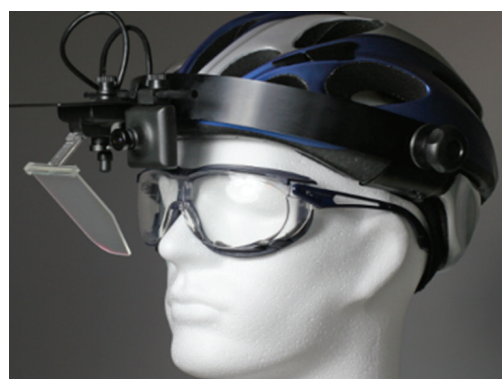

(a)

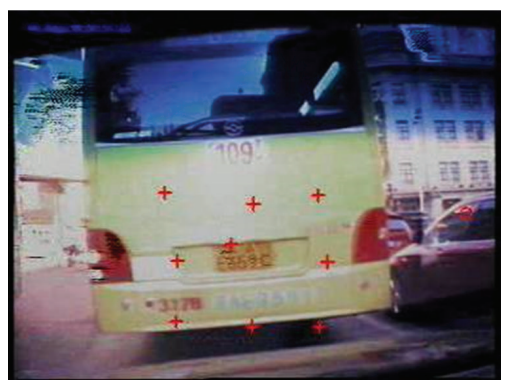

(d)

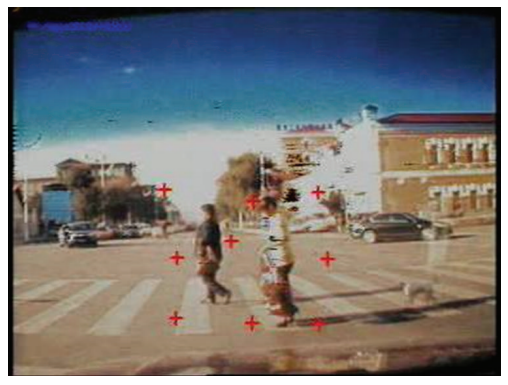

(g)

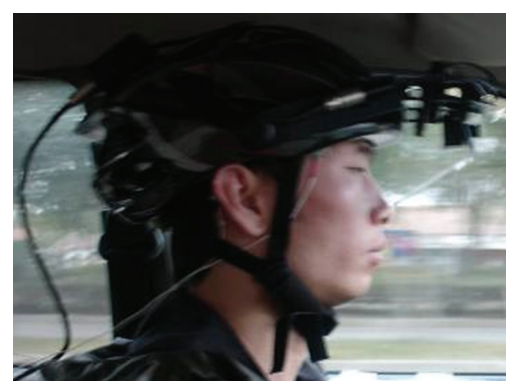

(b)

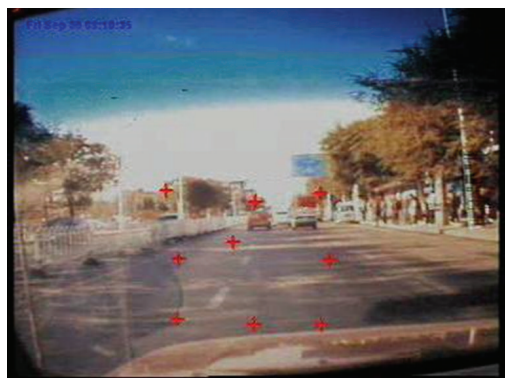

(e)

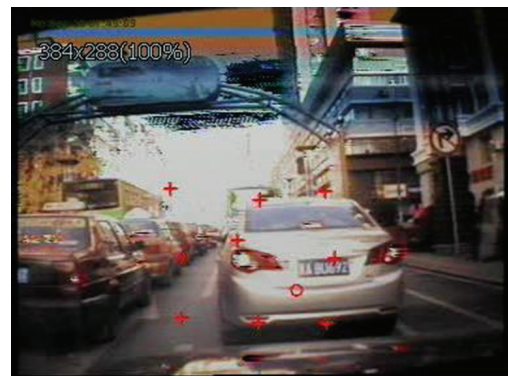

(h)

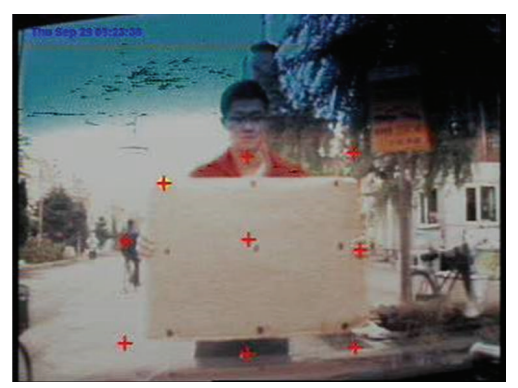

(c)

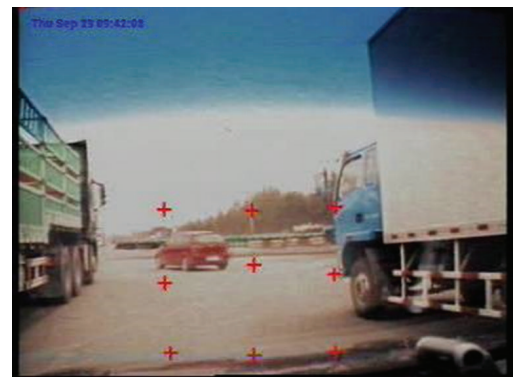

(f)

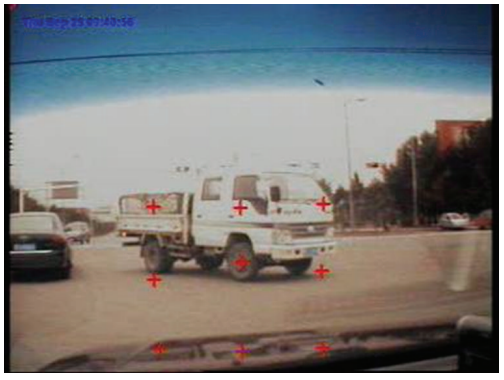

(i)

FIGURE 3: Test scenarios of driver's visual characteristics.

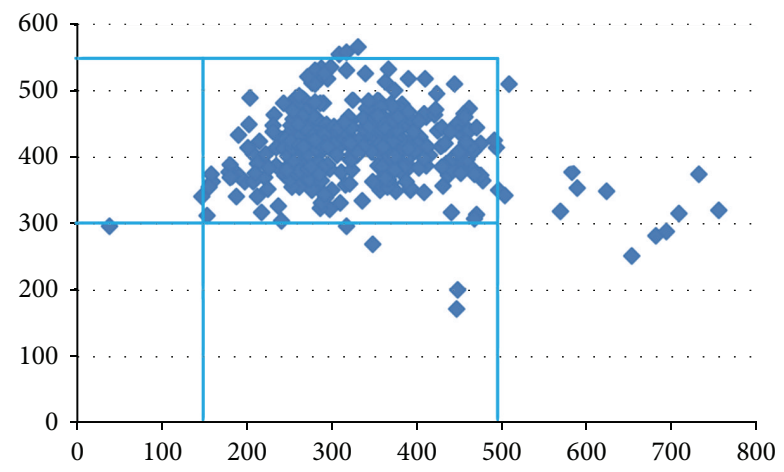

(a) General state

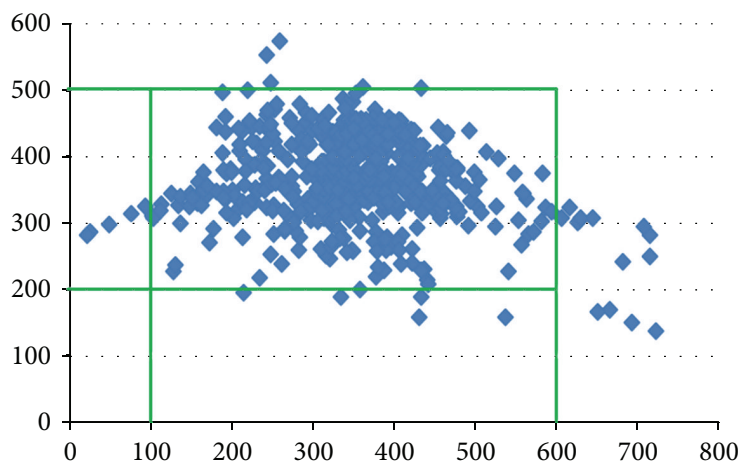

(b) Congested state

Figure 4: Planar distribution characteristics of driver's fixation points.

value and standard deviation of the average saccade speed are higher in congested state than those in general state. The average saccade speed in general and congested state generally obeys normal distribution other than log-normal distribution, as shown in Figures 7 and 8.
4.3.2. Average Saccade Acceleration. The statistical analysis results of drivers' average saccade acceleration are shown in Table 4. The mean value and standard deviation of the average saccade acceleration are different in general and congested state. The average saccade acceleration in general 


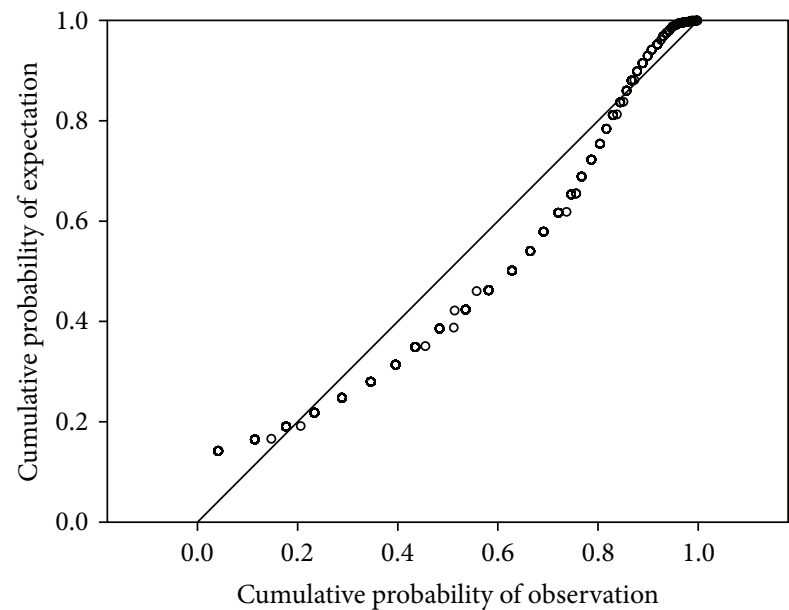

(a) General state

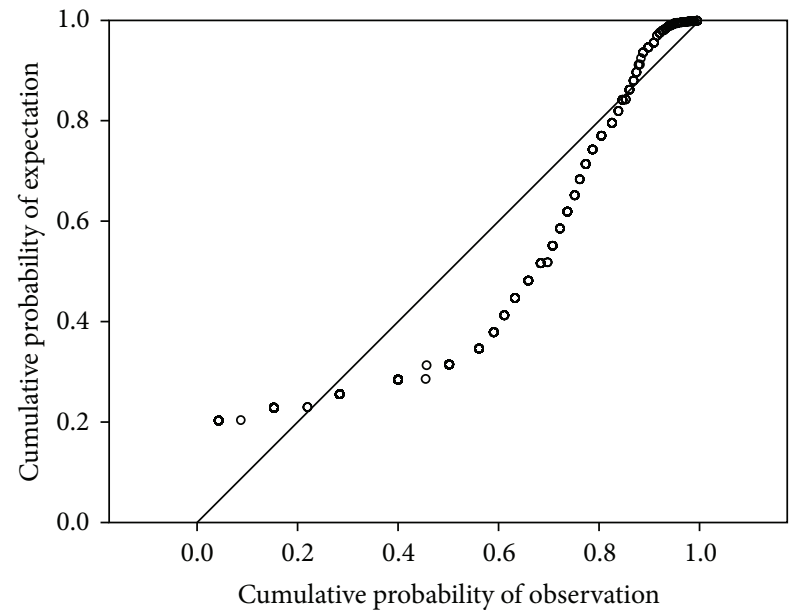

(b) Congested state

FIGURE 5: P-P figure of normal distribution fitting.

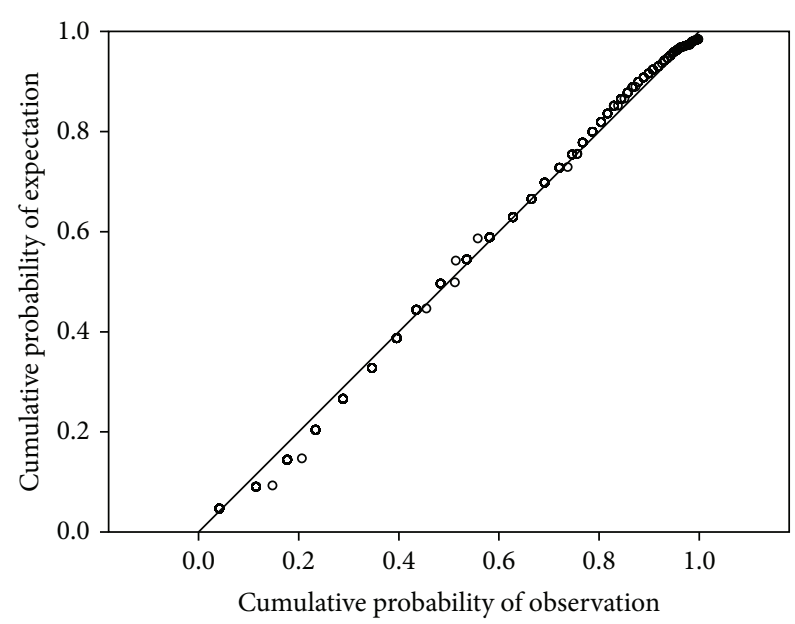

(a) General state

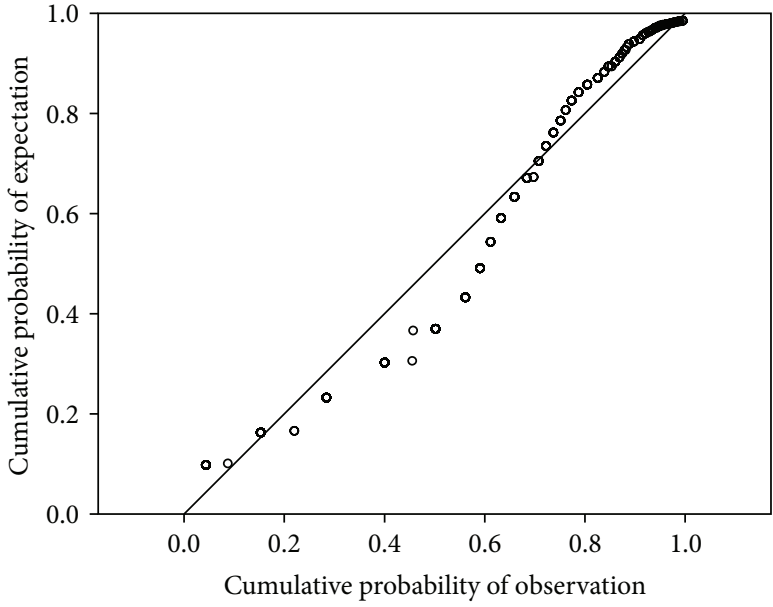

(b) Congested state

FIGURE 6: P-P figure of log-normal distribution fitting.

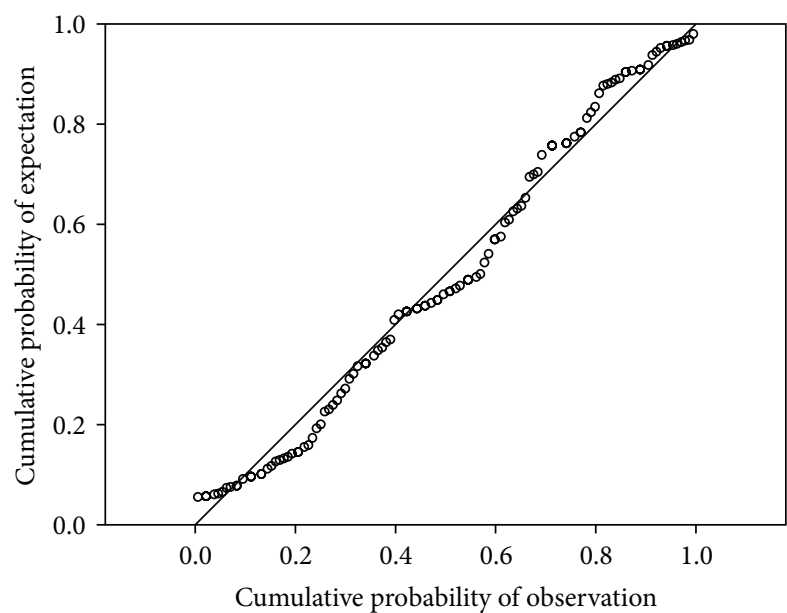

(a) General state

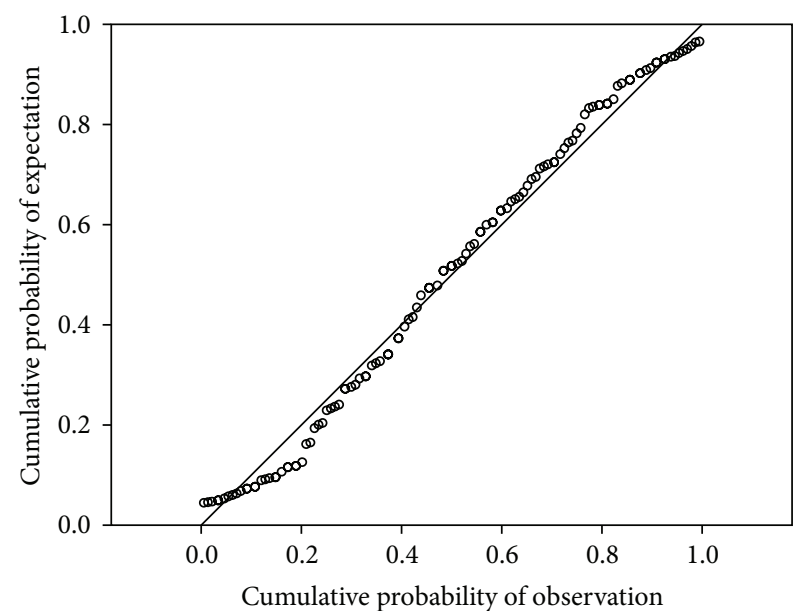

(b) Congested state

FIgURE 7: P-P figure of normal distribution fitting. 


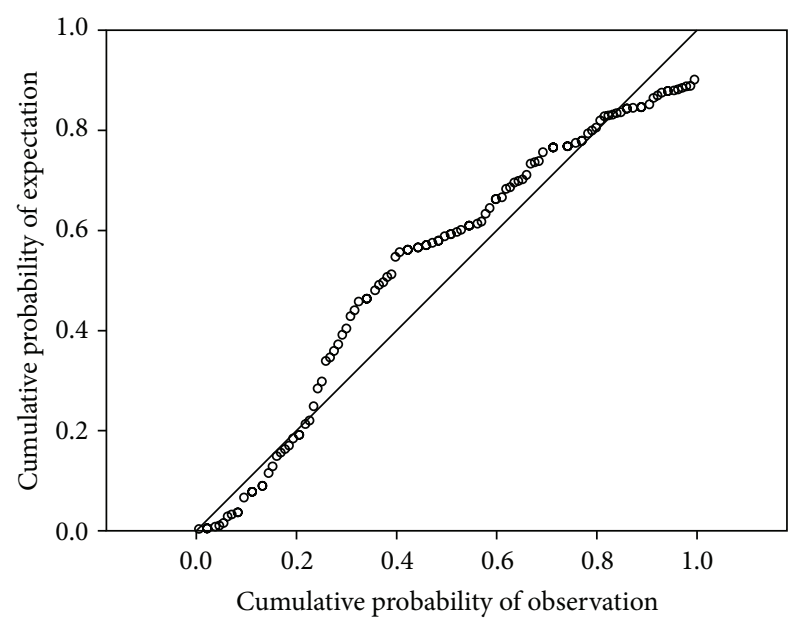

(a) General state

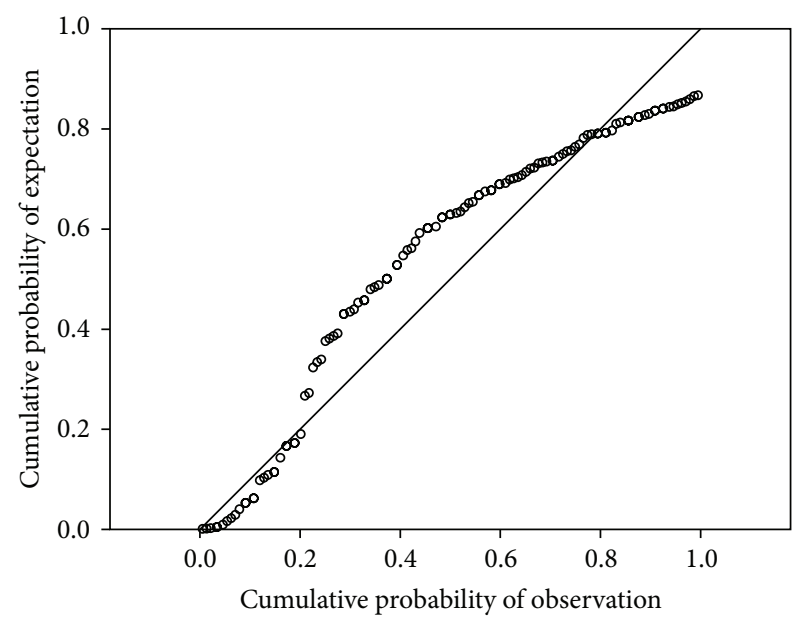

(b) Congested state

FIGURE 8: P-P figure of log-normal distribution fitting.

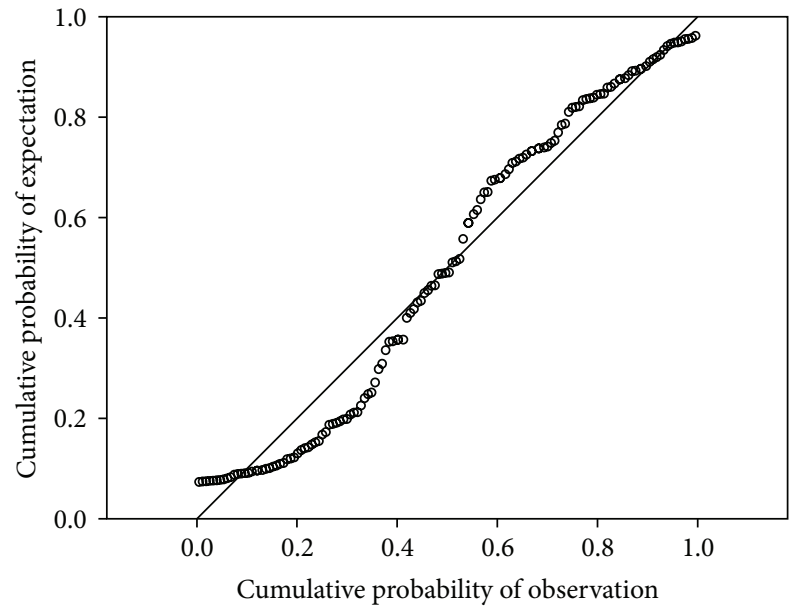

(a) General state

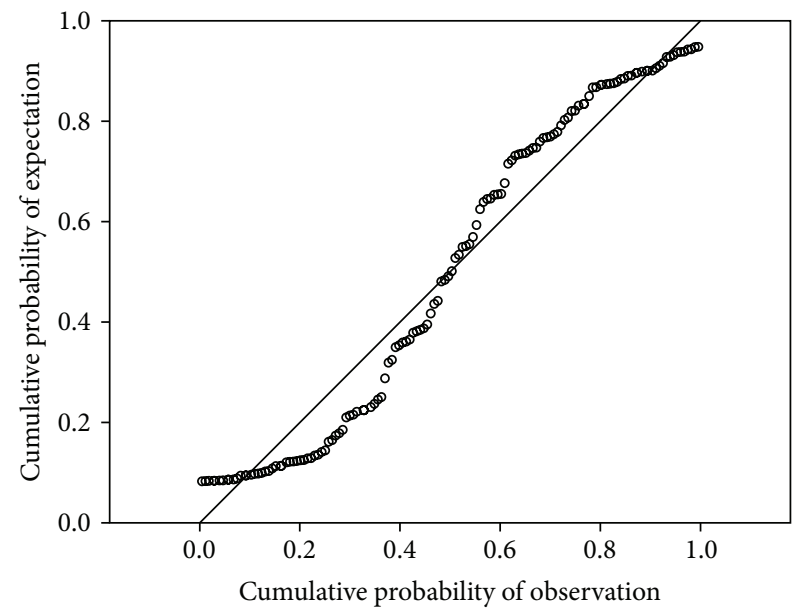

(b) Congested state

FIGURE 9: P-P figure of normal distribution fitting.

and congested state does not obey normal or log-normal distribution, as shown in Figures 9 and 10.

\subsection{Eye Blink}

4.4.1. Blink Duration. The statistical analysis results of drivers' blink duration are shown in Table 5. From Figures 11 and 12 , it can be concluded that the blink duration in general and congested state generally obeys log-normal distribution other than normal distribution.

4.4.2. Blink Rate. The statistical analysis results of drivers' blink rate are shown in Table 6 . The mean value and standard deviation of the blink rate are different in general and congested state. From Figures 13 and 14, it can be concluded that the blink rate in general and congested state generally obeys normal distribution and log-normal distribution.
4.5. Significance Test. Based on the foregoing analysis, the indicators of drivers' visual characteristics could not meet the requirements (normal distribution and variance homogeneity) for parameter test. Therefore, the nonparametric test method (Mann-Whitney $U$ test) is selected to test the difference significance for the indicators of drivers' visual characteristics in the general and congested state.

According to Table 7, the indicators of drivers' visual characteristics in the general and congested state are different in difference significance. Among them, the difference for the fixation duration and blink rate index is very significant $(P \leq 0.01)$; the difference for the average saccade speed and blink duration index is significant $(P \leq 0.05)$; but the difference for the average saccade acceleration index is not significant $(P>0.05)$. So, our research results suggest that traffic congestion has a strong effect on driver's visual characteristics. 
TABLE 2: Results of statistical analysis on the fixation duration.

\begin{tabular}{lccccc}
\hline No. & Sample & Average & Std. & Deviation & Kurtosis \\
\hline 1 & General state & 299 & 205 & 1.330 & 1.371 \\
2 & Congested state & 271 & 229 & 1.550 & 1.486 \\
\hline
\end{tabular}

TABLE 3: Results of statistical analysis on the average saccade speed.

\begin{tabular}{lccccc}
\hline No. & Sample & Average & Std. & Deviation & Kurtosis \\
\hline 1 & General state & 122 & 69 & 0.191 & -0.972 \\
2 & Congested state & 146 & 81 & -0.033 & -1.072 \\
\hline
\end{tabular}

TABLE 4: Results of statistical analysis on the average saccade acceleration.

\begin{tabular}{lccccc}
\hline No. & Sample & Average & Std. & Deviation & Kurtosis \\
\hline 1 & General state & 8704 & 5958 & 0.050 & -1.333 \\
2 & Congested state & 9129 & 6510 & 0.043 & -1.463 \\
\hline
\end{tabular}

TABLE 5: Results of statistical analysis on the blink duration.

\begin{tabular}{lccccc}
\hline No. & Sample & Average & Std. & Deviation & Kurtosis \\
\hline 1 & General state & 212 & 97 & 0.736 & -0.328 \\
2 & Congested state & 202 & 94 & 0.856 & -0.087 \\
\hline
\end{tabular}

TABLE 6: Results of statistical analysis on the blink rate.

\begin{tabular}{lccccc}
\hline No. & Sample & Average & Std. & Deviation & Kurtosis \\
\hline 1 & General state & 0.25 & 0.05 & 0.341 & -1.130 \\
2 & Congested state & 0.22 & 0.05 & -0.140 & -0.935 \\
\hline
\end{tabular}

TABLE 7: Difference significance for the indicators of drivers' visual characteristics.

\begin{tabular}{|c|c|c|c|c|c|c|}
\hline \multirow{2}{*}{ No. } & \multirow{2}{*}{ Index } & \multicolumn{2}{|c|}{ General state } & \multicolumn{2}{|c|}{ Congested state } & \multirow{2}{*}{ Sig. } \\
\hline & & Average & Std. & Average & Std. & \\
\hline 1 & $\begin{array}{l}\text { Fixation } \\
\text { duration }\end{array}$ & 299 & 205 & 271 & 229 & 0.000 \\
\hline 2 & $\begin{array}{l}\text { Average saccade } \\
\text { speed }\end{array}$ & 122 & 69 & 146 & 81 & 0.019 \\
\hline 3 & $\begin{array}{l}\text { Average saccade } \\
\text { acceleration }\end{array}$ & 8704 & 5958 & 9129 & 6510 & 0.553 \\
\hline 4 & Blink duration & 212 & 97 & 202 & 94 & 0.023 \\
\hline 5 & Blink rate & 0.25 & 0.05 & 0.22 & 0.05 & 0.006 \\
\hline
\end{tabular}

\section{Lane Changing Characteristics in Congested State}

5.1. Types and Statistical Characteristics of Risky Lane Changing. While driving in crowded traffic flow, drivers are subjected to the pressure of low speed, and they would change lanes to improve driving condition and gain higher speed. With the increase of congestion pressure, many drivers would choose risky lane changing behaviors to obtain bigger space, which may generate traffic conflicts. Risky lane changing behaviors are divided into three types according to their different characteristics.
(1) Lane changing directly: drivers directly import their vehicles into the target lane even if the headway does not meet the demands. It is a kind of risky lane changing behavior that would lead to serious conflicts.

(2) Lane changing pressingly: drivers continue to squeeze their vehicles into the target lane even if the headway does not meet the demands, and once enough space is gained, they are imported into the target lane immediately. It is a kind of risky lane changing behavior that would lead to certain conflicts.

(3) Lane changing selectively: drivers' vehicles and other vehicles in the target lane run in parallel, and drivers gradually turn their vehicles to the target lane even if the headway does not meet the demands. It is a kind of risky lane changing behavior that would lead to slight conflicts.

The statistical data of risky lane changing behaviors with different traffic parameters is as shown in Table 8. In Figures 15(a) and 15(b), we see that traffic volume and speed have the similar impact on the three types of risky lane changing behaviors. The percentage of lane changing selectively rises with the increase of traffic volume and speed, while the percentage of lane changing pressingly falls. Farther, the percentage of lane changing directly comes to its max value in the middle value of traffic volume and speed.

5.2. Relationship between Frequency of Risky Lane Changing and Traffic Conflicts. According to the selection of classification indexes for risky lane changing behaviors, influences for different types of risky lane changing behaviors on road safety are different, and the frequencies of risky lane changing and number of traffic conflicts per unit time at varied observation points are shown in Table 9.

The frequencies of lane changing directly, lane changing pressingly, and lane changing selectively are defined as independent variable of $X_{1}, X_{2}$, and $X_{3}$; the number of traffic conflicts is defined as a dependent variable of $Y$. A linear model of the traffic conflicts and different lane changing frequencies is established by regression analysis on data of Table 9. The model is shown in formula (4), and the value of residual and standard residual of the model which satisfies the requirements is shown in Table 10:

$$
Y=2.5 X_{1}+1.4 X_{2}+0.53 X_{3}+13.29
$$

According to the absolute value of the influence coefficient for all kinds of risky lane changing behaviors on traffic conflicts, behavior of lane changing directly has the most influence on road safety, in which drivers changing lane directly for once can lead to 2.5 times of traffic conflicts in average. Accordingly, behavior of lane changing selectively has the least influence on road safety, in which drivers changing lane selectively for once can lead to 0.53 times of traffic conflicts in average. 


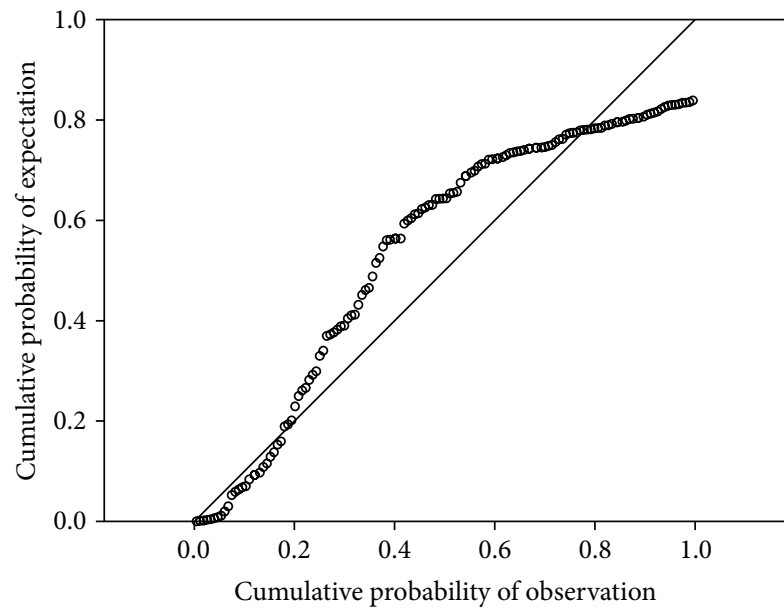

(a) General state

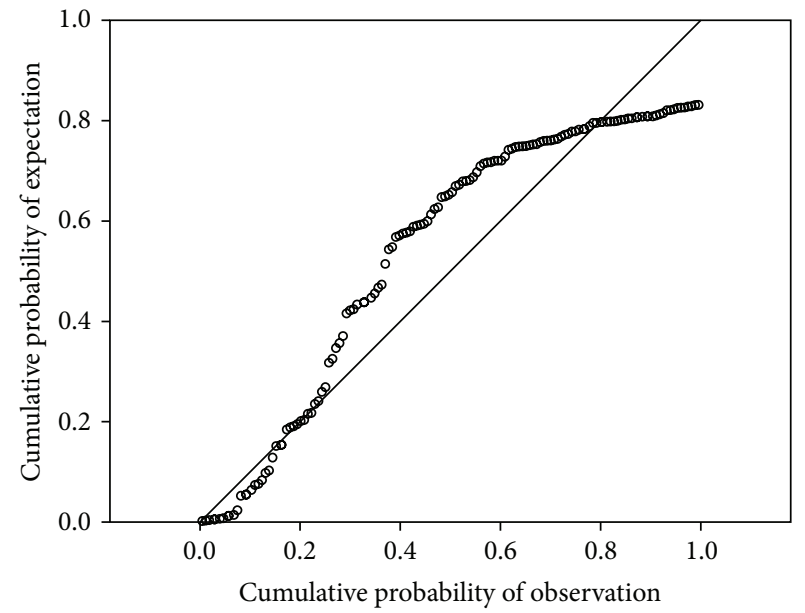

(b) Congested state

Figure 10: P-P figure of log-normal distribution fitting.

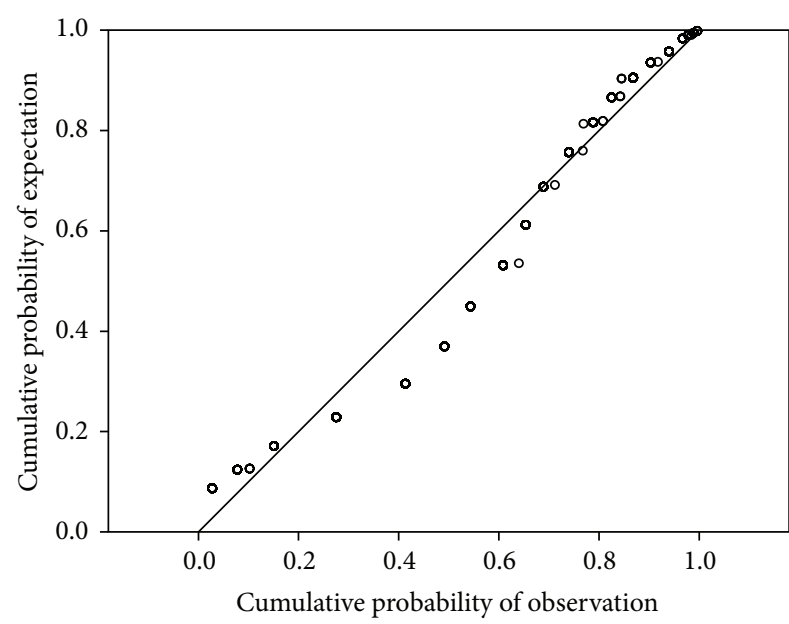

(a) General state

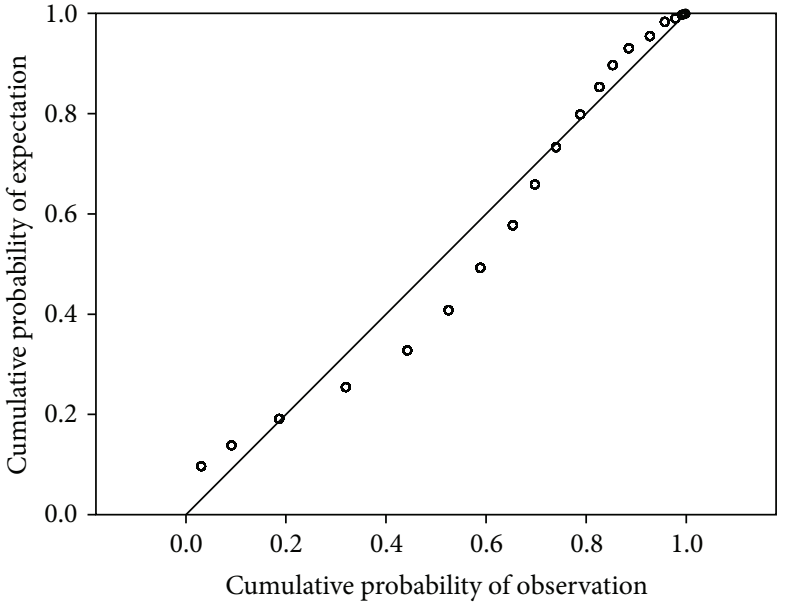

(b) Congested state

FIGURE 11: P-P figure of normal distribution fitting.

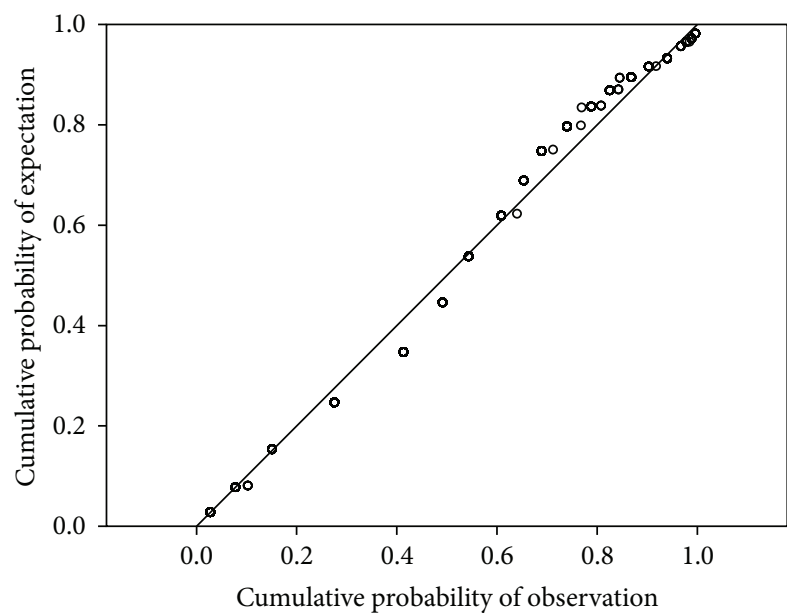

(a) General state

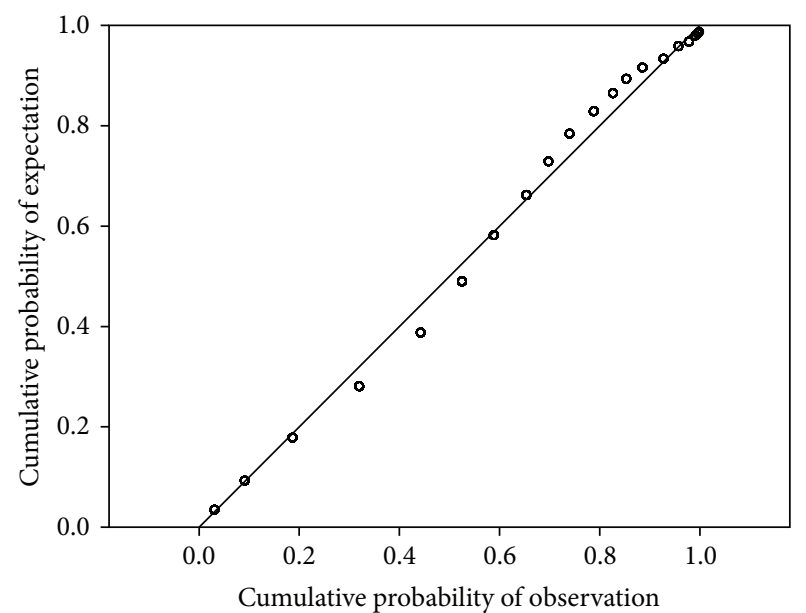

(b) Congested state

FIgURE 12: P-P figure of log-normal distribution fitting. 


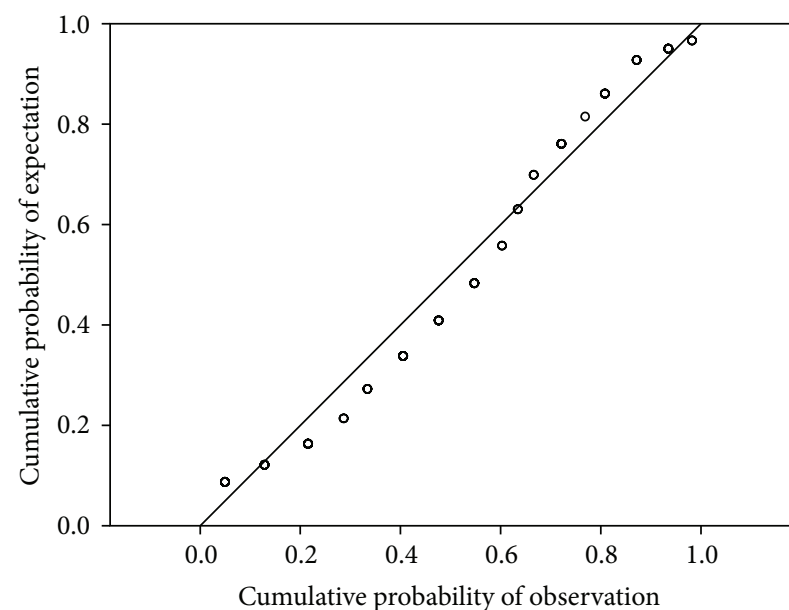

(a) General state

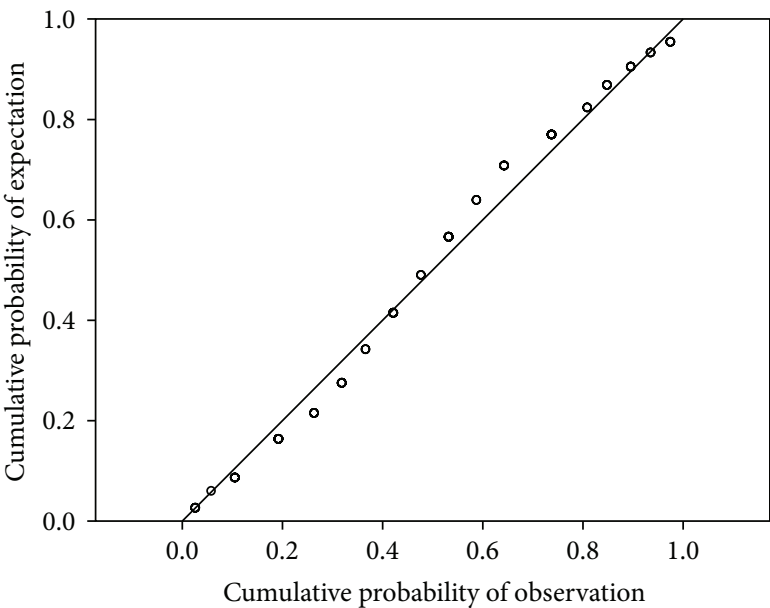

(b) Congested state

FIGURE 13: P-P figure of normal distribution fitting.

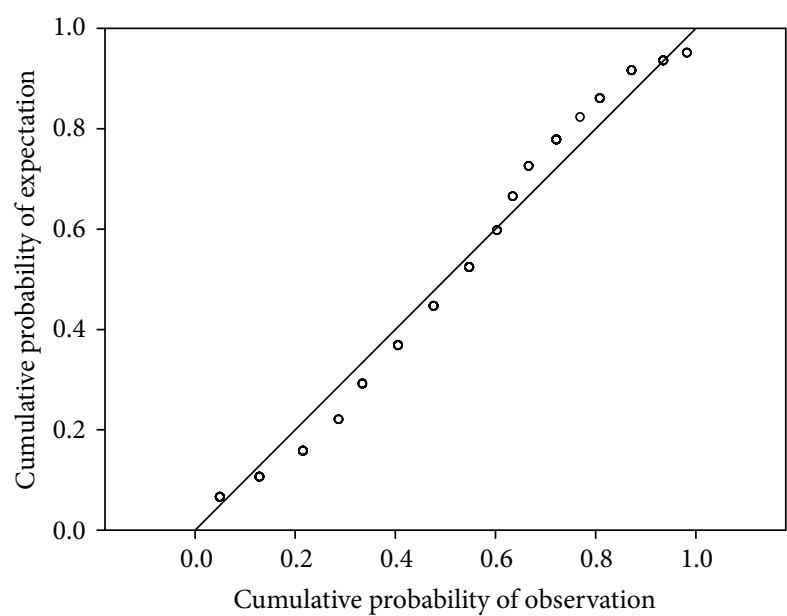

(a) General state

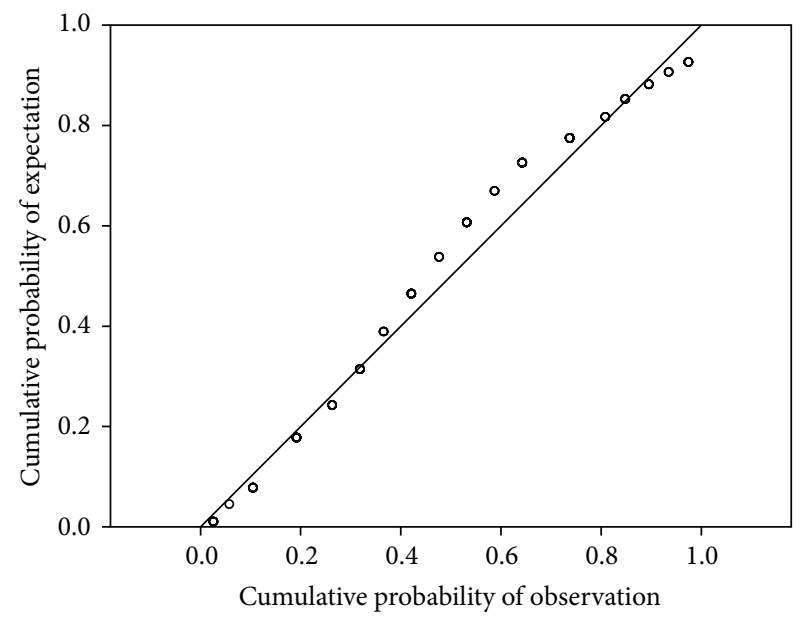

(b) Congested state

FIGURE 14: P-P figure of log-normal distribution fitting.

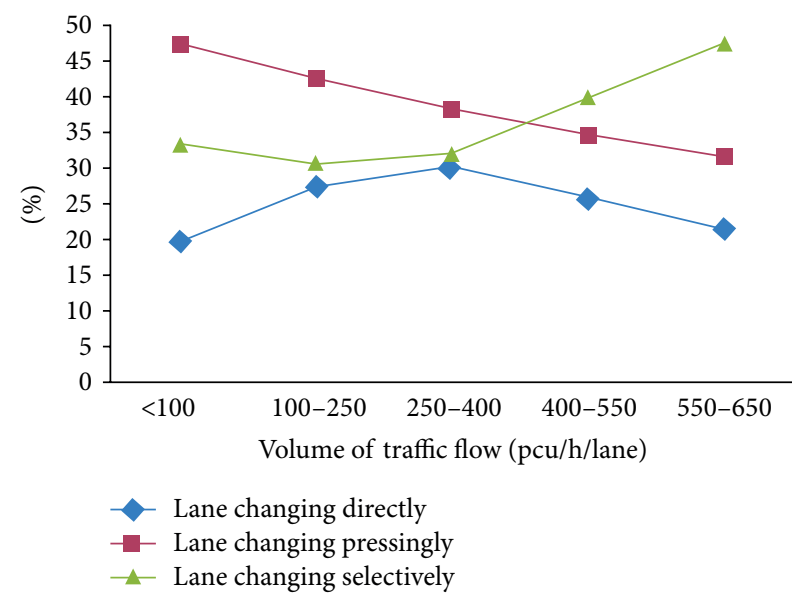

(a) Volume of traffic flow

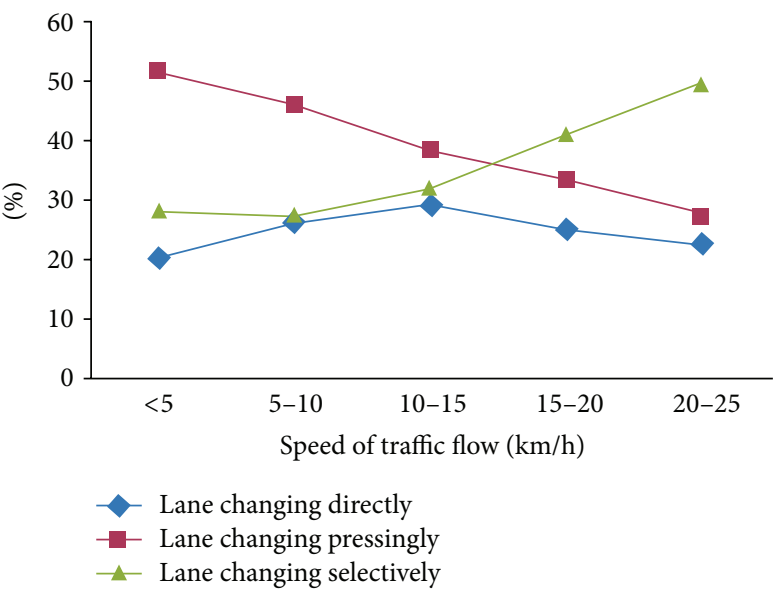

(b) Speed of traffic flow

FIGURE 15: Average weight of different risky lane changing behaviors in typical cities of China. 
TABLE 8: Statistical analysis of risky lane changing behaviors via different traffic parameters.

\begin{tabular}{lcccc}
\hline \multicolumn{2}{c}{ Type of risky lane changing } & Lane changing directly (\%) & Lane changing pressingly (\%) & Lane changing selectively (\%) \\
\hline & $<100$ & 19.71 & 47.18 & 33.11 \\
Volume of traffic flow & $100-250$ & 27.31 & 42.34 & 30.35 \\
(pcu/h/lane) & $250-400$ & 30.29 & 37.92 & 31.79 \\
& $400-550$ & 25.78 & 34.55 & 39.67 \\
& $550-650$ & 21.38 & 31.41 & 47.21 \\
\hline & $<5$ & 20.34 & 51.41 & 28.25 \\
Speed of traffic flow & $5-10$ & 26.52 & 46.13 & 27.35 \\
(km/h) & $10-15$ & 29.39 & 38.43 & 32.18 \\
& $15-20$ & 25.21 & 33.63 & 41.16 \\
& $20-25$ & 22.78 & 27.83 & 49.39 \\
\hline
\end{tabular}

TABLE 9: Statistical analyses for frequencies of risky lane changing and number of traffic conflicts.

\begin{tabular}{lcccc}
\hline \multirow{2}{*}{ No. } & \multicolumn{2}{c}{$\begin{array}{c}\text { Frequencies of risky lane changing behaviors (times/h) } \\
\text { Lane changing selectively }\end{array}$} & \multirow{2}{*}{ Traffic conflicts (times/h) } \\
\hline 1 & Lane changing directly & Lane changing pressingly & 19 & 143 \\
2 & 35 & 23 & 27 & 108 \\
3 & 12 & 18 & 15 & 107 \\
4 & 18 & 29 & 23 & 96 \\
5 & 16 & 22 & 25 & 119 \\
\hline
\end{tabular}

TABLE 10: Value of residual and standard residual of formula (4).

\begin{tabular}{lccccc}
\hline Prediction $Y$ & 143.10 & 107.81 & 106.85 & 96.28 & 118.96 \\
Residual & -0.0986 & 0.1899 & 0.1532 & -0.2801 & 0.0357 \\
Standard residual & -0.2555 & 0.4920 & 0.3968 & -0.7257 & 0.0924 \\
\hline
\end{tabular}

\section{Conclusion}

Drivers' physical and mental health in traffic congestion should attract more attention from traffic engineer and government administration. So, the impact of traffic congestion on drivers' eye movement and lane changing behavior has been quantified via the PSR model in this paper. In addition, the pressure coefficient has been defined to reflect drivers' feelings about the degree of traffic congestion; that traffic congestion has a strong effect on driver's visual characteristics has been proved via adequate data analysis; the risky lane changing behaviors in traffic congestion have been specifically analyzed.

The comparative analysis of the dynamic visual characteristics (fixation points' distribution, fixation duration, average saccade speed, average saccade acceleration, blink duration, and blink rate) is done via the data being obtained during rush hour. And, it is discovered that the eye movement characteristics are different between the general and congested state.

The characteristics of the risky lane changing behaviors are obtained through video monitoring, and the risky lane changing behaviors on the pressure of congestion have been divided into three types, and the proportion of the three types of risky lane changing behaviors is analyzed by statistical tools. Further, the linear relationship between the number of the traffic conflicts and risky lane changing is established to measure the security features for the risky lane changing in the pressure of traffic congestion.

\section{Conflict of Interests}

The authors declare that there is no conflict of interests regarding the publication of this paper.

\section{Acknowledgments}

The study was supported by the National Natural Science Foundation of China (51078113 and 51178149).

\section{References}

[1] J. D. Sun, Q. Liu, and Z.-R. Peng, "Research and analysis on causality and spatial-temporal evolution of urban traffic congestions-a case study on Shenzhen of China," Journal of Transportation Systems Engineering and Information Technology, vol. 11, no. 5, pp. 86-93, 2011.

[2] R. Arnott, "A bathtub model of downtown traffic congestion," Journal of Urban Economics, vol. 76, pp. 110-121, 2013.

[3] T. Tsekeris and N. Geroliminis, "City size, network structure and traffic congestion," Journal of Urban Economics, vol. 76, pp. 1-14, 2013.

[4] S. Yang, "On feature selection for traffic congestion prediction," Transportation Research Part C, vol. 26, pp. 160-169, 2013. 
[5] B. L. Smith, B. M. Williams, and R. K. Keith Oswald, "Comparison of parametric and nonparametric models for traffic flow forecasting," Transportation Research Part C, vol. 10, no. 4, pp. 303-321, 2002.

[6] B. M. Williams and L. A. Hoel, "Modeling and forecasting vehicular traffic flow as a seasonal ARIMA process: theoretical basis and empirical results," Journal of Transportation Engineering, vol. 129, no. 6, pp. 664-672, 2003.

[7] S. R. Chandra and H. Al-Deek, "Predictions of freeway traffic speeds and volumes using vector autoregressive models," Journal of Intelligent Transportation Systems, vol. 13, no. 2, pp. 53-72, 2009.

[8] D. A. Hennessy and D. L. Wiesenthal, "The relationship between traffic congestion, driver stress and direct versus indirect coping behaviours," Ergonomics, vol. 40, no. 3, pp. 348-361, 1997.

[9] D. A. Hennessy and D. L. Wiesenthal, "Traffic congestion, driver Stress, and driver aggression," Aggressive Behavior, vol. 25, no. 6, pp. 409-423, 1999.

[10] B.-H. Liu, L.-S. Sun, and J. Rong, "Driver's visual cognition behaviors of traffic signs based on eye movement parameters," Journal of Transportation Systems Engineering and Information Technology, vol. 11, no. 4, pp. 22-27, 2011.

[11] T. C. Lansdown, "Individual differences during driver secondary task performance: verbal protocol and visual allocation findings," Accident Analysis and Prevention, vol. 34, no. 5, pp. 655-662, 2002.

[12] G. Underwood, D. Crundall, and P. Chapman, "Selective searching while driving: the role of experience in hazard detection and general surveillance," Ergonomics, vol. 45, no. 1, pp. 1-12, 2002.

[13] S. Benedetto, M. Pedrotti, L. Minin, T. Baccino, A. Re, and R. Montanari, "Driver workload and eye blink duration," Transportation Research Part F, vol. 14, no. 3, pp. 199-208, 2011.

[14] J. L. Deffenbacher, R. S. Lynch, E. R. Oetting, and D. A. Yingling, "Driving anger: correlates and a test of state-trait theory," Personality and Individual Differences, vol. 31, no. 8, pp. 1321-1331, 2001.

[15] J. L. Deffenbacher, R. S. Lynch, E. R. Oetting, and R. C. Swaim, "The driving anger expression inventory: a measure of how people express their anger on the road," Behaviour Research and Therapy, vol. 40, no. 6, pp. 717-737, 2002.

[16] M. J. M. Sullman, "Anger amongst New Zealand drivers," Transportation Research Part F, vol. 9, no. 3, pp. 173-184, 2006.

[17] D. J. Rapport and A. M. Friend, Towards a Comprehensive Framework for Environmental Statistics: A Stress-Response Approach, Statistics Canada, Ottawa, Canada, 1979.

[18] D. J. Rapport and A. Singh, "An EcoHealth-based framework for State of Environment Reporting," Ecological Indicators, vol. 6, no. 2, pp. 409-428, 2006.

[19] D. Zhou, Z. Lin, L. Liu, and D. Zimmermann, "Assessing secondary soil salinization risk based on the PSR sustainability framework," Journal of Environmental Management, vol. 128, pp. 642-654, 2013.

[20] K. Lundberg, B. Balfors, and L. Folkeson, "Framework for environmental performance measurement in a Swedish public sector organization," Journal of Cleaner Production, vol. 17, no. 11, pp. 1017-1024, 2009.

[21] R. W. Novaco, D. Stokols, and L. Milanesi, "Objective and subjective dimensions of travel impedance as determinants of commuting stress," American Journal of Community Psychology, vol. 18, no. 2, pp. 231-257, 1990.
[22] E. Gulian, G. Matthews, A. I. Glendon, D. R. Davies, and L. M. Debney, "Dimensions of driver stress," Ergonomics, vol. 32, no. 6, pp. 585-602, 1989. 


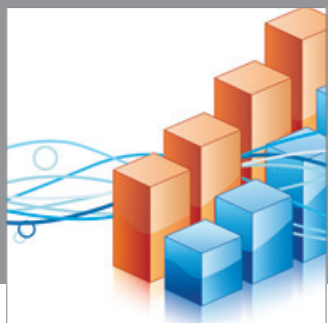

Advances in

Operations Research

mansans

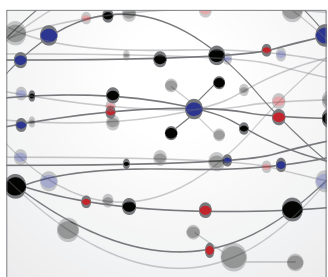

The Scientific World Journal
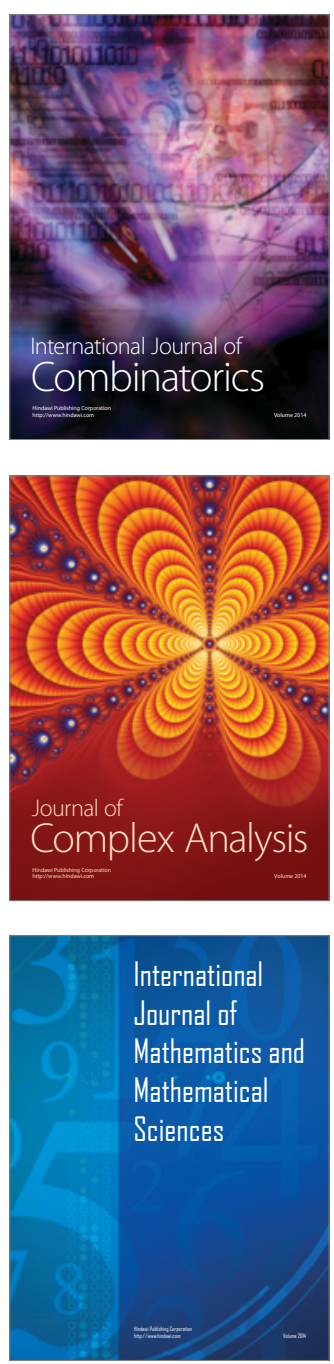
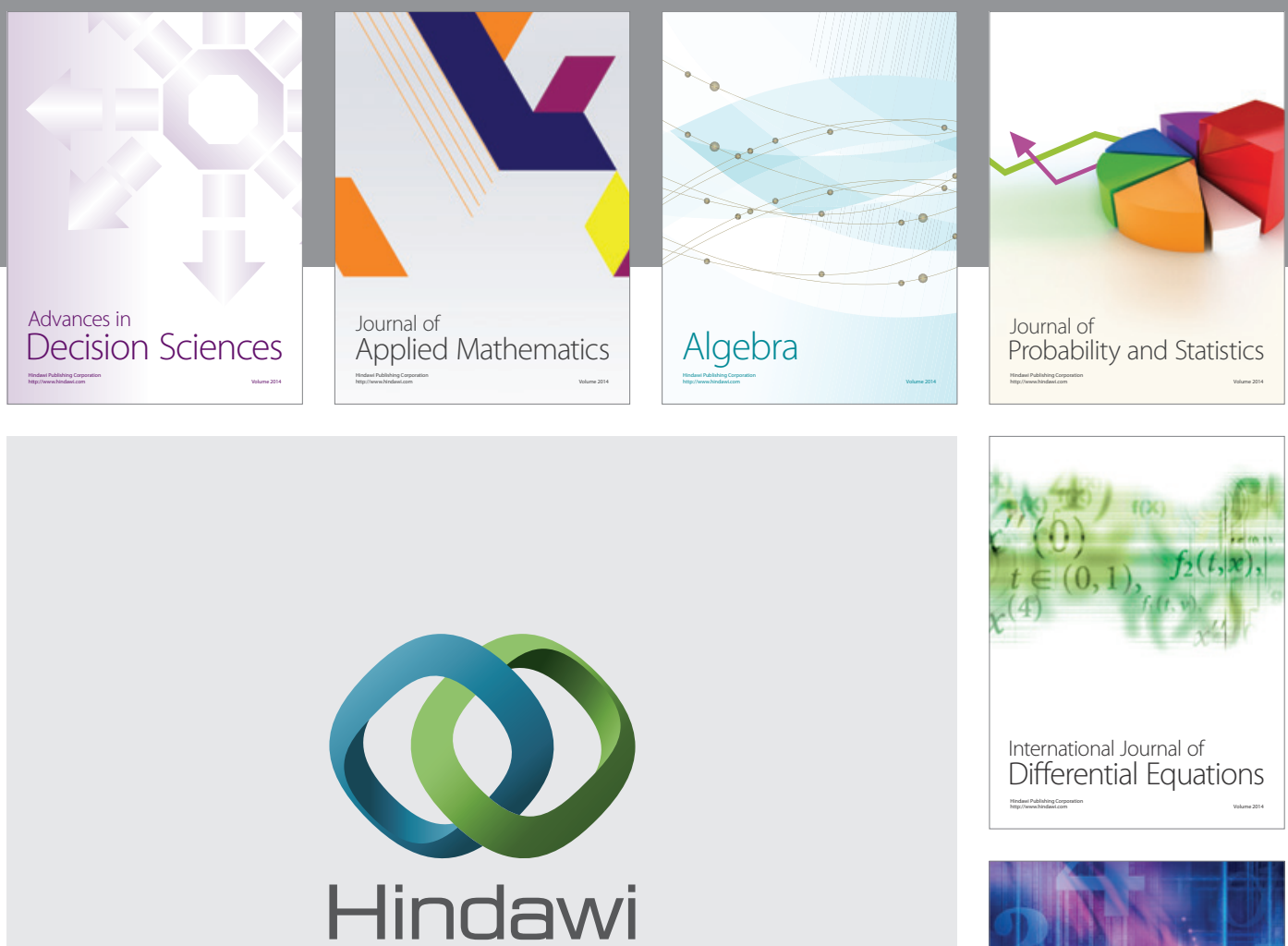

Submit your manuscripts at http://www.hindawi.com
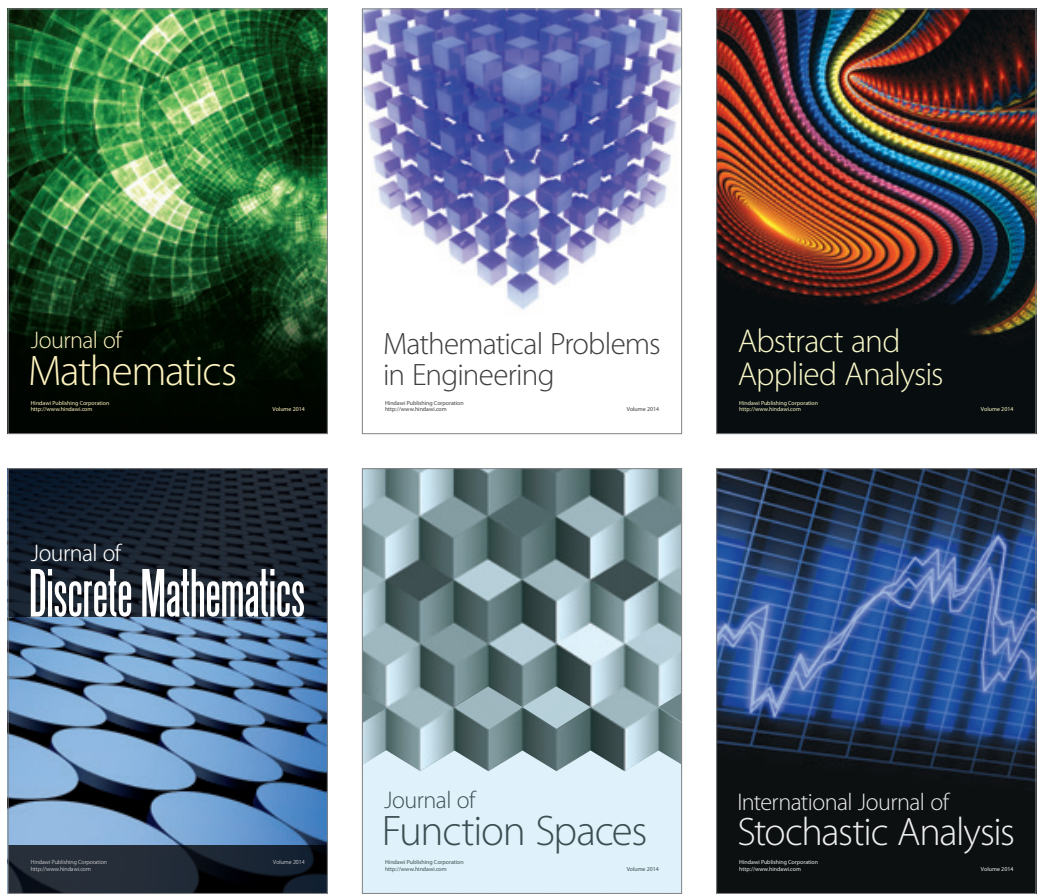

Journal of

Function Spaces

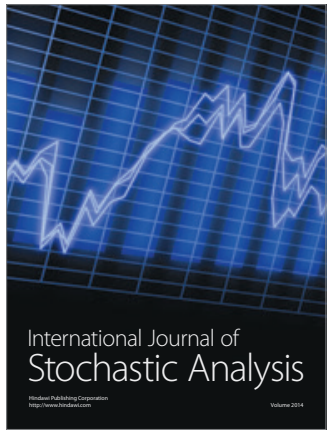

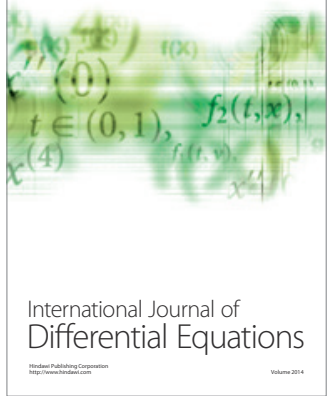
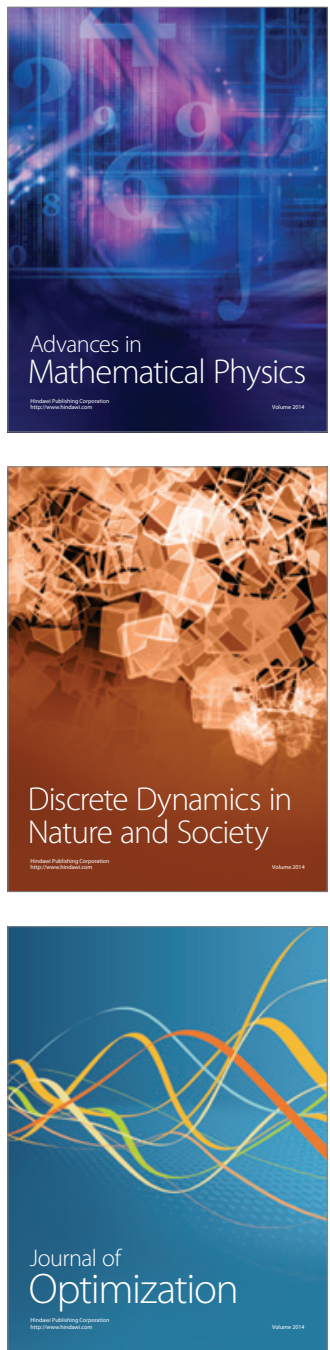